\title{
How plot shape and spatial arrangement affect plant species richness counts: implications for sampling design and rarefaction analyses
}

\author{
Behlül Güler, Anke Jentsch, Iva Apostolova, Sándor Bartha, Juliette M.G. Bloor, Giandiego \\ Campetella, Roberto Canullo, Judit Házi, Jürgen Kreyling, Julien Pottier, Gábor Szabó, \\ Tsvetelina Terziyska, Emin Uğurlu, Camilla Wellstein, Zita Zimmermann \& Jürgen Dengler
}

\begin{abstract}
Keywords
Biodiversity; Discontiguous; Effective area; Grassland; Sampling unit; Scale dependence; Spatial autocorrelation; Spatial extent; Spatial grain; Species-area relationship; Speciesextent relationship; Vegetation plot
\end{abstract}

\author{
Abbreviations \\ $A_{e}=$ effective area; $S A R=$ species - area \\ relationship; SAER = species-area-extent \\ relationship; SER = species-extent relationship; \\ $\mathrm{STAR}=$ species-time-area relationship; \\ $\mathrm{STR}=$ species-time relationship. \\ Received 11 October 2015 \\ Accepted 29 February 2016 \\ Co-ordinating Editor: János Podani
}

Güler, B. (behlul.guler@cbu.edu.tr) ${ }^{1,2}$, Jentsch, A. (anke.jentsch@uni-bayreuth.de) 2,3, Apostolova, I. (iva.apostolova@gmail.com) ${ }^{4}$, Bartha, S.

(bartha.sandor@okologia.mta.hu) $)^{5,6}$, Bloor, J.M. (juliette.bloor@clermont.inra.fr) ${ }^{7}$, Campetella, G.

(diego.campetella@unicam.it) ${ }^{8}$, Canullo, R. (roberto.canullo@unicam.it) ${ }^{8}$, Házi, J. (hazijudit246@gmail.com) ${ }^{9}$, Kreyling, J. (juergen.kreyling@ uni-greifswald.de) ${ }^{10}$,

Pottier, J. (julien.pottier@clermont.inra.fr) ${ }^{7}$, Szabó, G. (szabo.gabor@okologia.mta.hu) ${ }^{5}$, Terziyska, T. (ts.terziyska@gmail.com) ${ }^{4}$, Uğurlu, E. (ugurlu@yahoo.com) ${ }^{1,11}$, Wellstein, C. (camilla.wellstein@unibz.tit) ${ }^{12}$, Zimmermann, Z.

(zimmermann.zita@okologia.mta.hu) ${ }^{5}$, Dengler, J. (corresponding author, juergen.dengler@uni-bayreuth.de) 3,13,14

${ }^{1}$ Biology, Faculty of Science \& Letters, Celal Bayar University, Muradiye Campus, 45040 Manisa, Turkey;

${ }^{2}$ Disturbance Ecology, University of Bayreuth, Universitätsstr. 30, 95447 Bayreuth, Germany; ${ }^{3}$ Bayreuth Center of Ecology and Environmental Research (BayCEER), University

\begin{abstract}
Questions: How does the spatial configuration of sampling units influence recorded plant species richness values at small spatial scales? What are the consequences of these findings for sampling methodology and rarefaction analyses?

Location: Six semi-natural grasslands in Western Eurasia (France, Germany, Bulgaria, Hungary, Italy, Turkey).

Methods: In each site we established six blocks of $40 \mathrm{~cm} \times 280 \mathrm{~cm}$, subdivided into $5 \mathrm{~cm} \times 5 \mathrm{~cm}$ micro-quadrats, on which we recorded vascular plant species presence with the rooted (all sites) and shoot (four sites) presence method. Data of these micro-quadrats were then combined to achieve larger sampling units of $0.01,0.04$ and $0.16 \mathrm{~m}^{2}$ grain size with six different spatial configurations (square, 4:1 rectangle, 16:1 rectangle, three variants of discontiguous randomly placed micro-quadrats). The effect of the spatial configurations on species richness was quantified as relative richness compared to the mean richness of the square of the same surface area.
\end{abstract}

Results: Square sampling units had significantly lower species richness than other spatial configurations in all countries. For 4:1 and 16:1 rectangles, the increase of rooted richness was on average about $2 \%$ and $8 \%$, respectively. In contrast, the average richness increase for discontiguous configurations was 7\%, $17 \%$ and $40 \%$. In general, increases were higher with shoot presence than with rooted presence. Overall, the patterns of richness increase were highly consistent across six countries, three grain sizes and two recording methods.

Conclusions: Our findings suggest that the shape of sampling units has negligible effects on species richness values when the length-width ratio is up to 4:1, and the effects remain small even for more elongated contiguous configurations. In contrast, results from discontiguous sampling units are not directly comparable with those of contiguous sampling units, and are strongly confounded by spatial extent. This is particularly problematic for rarefaction studies where spatial extent is often not controlled for. We suggest that the concept of effective area is a useful tool to report effects of spatial configuration on richness values, and introduce species-extent relationships (SERs) to describe richness increases of different spatial configurations of sampling units. 
of Bayreuth, Universitätsstr. 30, 95447

Bayreuth, Germany;

${ }^{4}$ Institute of Biodiversity and Ecosystem

Research, Bulgarian Academy of Sciences, 23

Acad. G. Bonchev Str., 11113 Sofia Sofia,

Bulgaria;

${ }^{5}$ Institute of Ecology and Botany, MTA Centre for

Ecological Research, Alkotmány u. 2-4, 2163

Vácrátót, Hungary;

${ }^{6}$ School of Plant Biology, The University of

Western Australia, 35 Stirling Highway, Crawley,

WA 6009, Australia;
${ }^{7}$ Grassland Ecosystem Research Team, UR874, INRA, 5 Chemin de Beaulieu, 63039 ClermontFerrand, France;

${ }^{8}$ Plant Diversity and Ecosystems Management Unit, School of Biosciences \& Veterinary Medicine, University of Camerino, Via Pontoni 5, 62032 Camerino (MC), Italy;

${ }^{9}$ Institute of Botany and Ecophysiology, Szent István University, Páter K. u. 1, 2100 Gödöllo”, Hungary;

${ }^{10}$ Experimental Plant Ecology, Institute of Botany and Landscape Ecology, University of Greifswald, Soldmannstr. 15, 17487 Greifswald, Germany;

\author{
${ }^{11}$ Forest Engineering, Faculty of Forestry, Bursa \\ Technical University, 152 Evler Str. 2/10, 16330 \\ Yıldırım, Bursa, Turkey; \\ ${ }^{12}$ Faculty of Science and Technology, Free \\ University of Bozen, Piazza Università 5, 39100 \\ Bozen, Italy; \\ ${ }^{13}$ Plant Ecology, University of Bayreuth, \\ Universitätsstr. 30, 95447 Bayreuth, Germany; \\ ${ }^{14}$ German Centre for Integrative, Biodiversity \\ Research (iDiv) Halle-Jena-Leipzig, Deutscher \\ Platz 5e, 04103 Leipzig, Germany
}

\section{Introduction}

In ecology and conservation, species richness is probably the most frequently used measure of diversity because it is easily measurable in a multitude of different situations and comprehensible even for non-specialists. Accurate quantification of species richness requires appropriate sampling decisions regarding sample size, the selection and configuration of sampling units (in vegetation science called quadrats, vegetation plots or just plots), as well as their size and shape (Kenkel et al. 1989; Bacaro et al. 2015). Given that species richness on average increases with area (Arrhenius 1921; Connor \& McCoy 1979; Dengler 2009), comparisons of species richness counts are usually only meaningful between sampling units of the same grain size. However, there are at least three other factors that can distort comparisons of species richness for a given area: (1) the shape of the sampling unit used to assess species richness (elongated vs compact); (2) the dispersion or contingency of subplots that constitute the overall area to be quantified (spatial arrangement; contiguous vs discontiguous); and (3) in the case of plants and other sessile organisms, the method by which an individual is considered present in the plot (shoot presence, rooted presence, grid-point presence; Dengler 2008).

Essentially all geographic phenomena are subject to the distance decay of similarity (the first law of geography: Tobler 1970; Nekola \& Brown 2007), which is also true for ecological and biogeographic patterns, such as species composition (Harte et al. 1999; Nekola \& White 1999). This means that two plant assemblages sampled geographically closer to each other, be it plant communities or regional floras, are on average more similar than those sampled at a larger distances. This is universally true for very local scales, such as a few meters (e.g. Dengler 2006), and for large distances, such as several thousands of kilometres (e.g. Nekola $\delta$ White 1999). The distance decay in plant species composition has two main drivers (Nekola \& White 1999): first, the distance decay in climate, soil, topography, composition of species of other trophic levels, as well as of human land-use patterns creates environmental filters that become, on average, more and more dissimilar with distance, thus selecting for increasingly different plant species composition. Second, biological processes of the plant species themselves are strongly distance-dependent, such as lateral spread, dispersal, gene flow and species-species interactions, including facilitation or parasitism. Such biological processes can even overrule - to some extent - environmental filtering, leading to the occurrence of species in ecologically suboptimal habitats which are spatially close to ecologically optimal source habitats. This phenomenon occurs both at local and at biogeographic distances and has been termed 'mass effect' (Shmida \& Wilson 1985) or 'vicinism' (Zonneveld 1994). Generally, distance decay in compositional similarity of plant assemblages should be relatively low when there are less pronounced environmental gradients and/or when species with good dispersal ability of diaspores and genes are considered, and vice versa. If we accept the universality of the distance decay, it is selfevident that sampling units, which cover a larger spatial distance ('extent' sensu Scheiner et al. 2000) yet have the same total area ('grain' sensu Scheiner et al. 2000), should on average comprise more species. This argument equally holds for elongated vs compact shapes of plots and for discontiguous vs contiguous configurations.

While theoretically it is clear that less compact plots should lead to a higher recorded species number, this fact is rarely considered in sampling recommendations in vegetation science. For example, the methodological textbook of Kent (2012) does not mention plot shape at all, while Knapp (1984) discusses the pros and cons of squares vs circles vs rectangles, mainly based on practical considerations, such as effort needed to delimit the plot in the field and risk of overlooking spe- 
cies. In large homogenous stands, compact forms such as squares or circles are generally used for phytosociological sampling, whereas in vegetation mosaics rectangular and irregularly shaped plots are recommended to minimize the within-plot heterogeneity (Dierschke 1994). In the context of biodiversity monitoring, elongated shapes are sometimes recommended because they allow capturing of more species on the same surface area, which is considered more 'efficient' (e.g. Stohlgren 2007; Bacaro et al. 2015). However, the few studies examining impacts of different sampling unit shapes have generated contrasting results, and it is hard to assess the magnitude of 'plot shape' effects. At small grain sizes $\left(0.25-1.00 \mathrm{~m}^{2}\right)$, for example, one study found increases of $1.4-1.6 \%$ in richness (Bossuyt \& Hermy 2004), while another reported $40 \%$ higher richness (Stohlgren 2007) compared to squares of the same size. At a grain size of $16 \mathrm{~m}^{2}$, Kunin (1997) found $5.5 \%$ more species in $16: 1$ rectangles than in either $4: 1$ rectangles or squares. In contrast, Keeley $\&$ Fotheringham (2005) found 4:1 rectangles of 1 and $100 \mathrm{~m}^{2}$ to exhibit the same or even an insignificantly lower richness than squares of the same size. At intermediate grain sizes (habitat patches within $1-\mathrm{km}^{2}$ landscape segments), Heegaard et al. (2007) reported strong positive effects of the degree of elongation on species richness, with a more than doubled richness in the most elongated patches compared to circles, on average. At much larger grain sizes of 32, 160 and $800 \mathrm{~km}^{2}$ (distribution atlas data), Kunin (1997) found consistent and significant increases of about $6 \%$ for $4: 1$ rectangles and $16 \%$ for $16: 1$ rectangles in relation to squares.

For primary sampling, vegetation ecologists normally use contiguous sample units (but see Dierschke 1994, who considers combining dispersed subplots into one virtual sampling unit admissible in phytosociology). However, in later analytical steps, the species data of several discontiguous primary plots are often combined to form 'virtual plots'. This is particularly common for so-called species accumulation or rarefaction curves (hereafter referred to as rarefaction curves), which are a fashionable tool in biodiversity research (Gotelli \& Colwell 2001, 2011), and are also widely used for comparison of different vegetation types (e.g. Stiles \& Scheiner 2007) or floras (e.g. Koellner et al. 2004). However, the users of rarefaction curves often overlook the underlying assumptions of this technique. First, sampling units used for the construction of rarefaction curves need to be randomly distributed in the area of inference (Gotelli \& Colwell 2011), and second, rarefaction curves of different types (vegetation, land use, ...) can only be statistically compared when they are based on the same spatial extent (Chiarucci et al. 2009; Dengler \& Oldeland 2010). The latter two studies showed with real and simulated data, respectively, that rarefaction curves of the same vegetation type have extremely different values depending on the spatial extent. This finding, an obvious consequence of the distance decay, questions results of many studies using rarefaction methods but not controlling for spatial extent. Due to the scarcity of methodological studies in this field, it is currently unclear how big the distorting effect of varying spatial extents is at the plot scale. However, in recent work with distribution data of different taxa (4-100 $\left.\mathrm{km}^{2}\right)$, Lazarina et al. (2014) convincingly demonstrated that combining non-contiguous plots into richness counts leads to dramatically higher richness values than in contiguous areas.

Despite strong theoretical grounds for expecting significant impacts of sampling unit shape and spatial arrangement on species richness counts and the few methodological studies that supported this expectation, the potential influence of differences in shape (degree of elongation) and contingency (degree of dispersion) are generally ignored in ecological studies. Here we aim to improve knowledge on effects of these two components of spatial configuration on derived plant species richness values. Following Li \& Reynolds (1995), we call them plot shape and spatial arrangement, respectively, and use spatial configuration when we refer to both aspects together. In order to obtain results of high generality, we conducted a standardized study at six different grassland sites in six different Eurasian countries (multi-site approach), examined three different spatial grain sizes and compared the two most frequently used recording principles in vegetation ecology (shoot vs rooted). Specifically, we set out to (1) quantify the importance of sampling unit shape and spatial arrangement for plant species richness counts, and (2) determine whether the size of these effects depend on grain size, recording principles and characteristics of the vegetation type being studied.

\section{Methods}

\section{Study sites and plots}

The sampling was conducted within the framework of the BiodivERsA project SIGNAL (http://www.bayceer.unibayreuth.de/signal/; see Jentsch et al. 2014). In each of six western Palaearctic countries along a steep climatic gradient (France, Germany, Bulgaria, Hungary, Italy, Turkey; see Appendix S1 for geo-locations and site characteristics) we established one experimental study site of approx. $30 \mathrm{~m} \times 15 \mathrm{~m}$ in semi-natural grassland representative of their respective regions. The sites contained stands of vegetation managed agriculturally (mowing or extensive graz- 
ing) prior to the start of the SIGNAL project, selected to be as homogenous as possible. At each site we established six

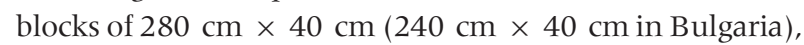
separated from each other by a minimum of $3 \mathrm{~m}$ and a maximum of $30 \mathrm{~m}$. The spatial arrangement of the six blocks slightly varied between countries to avoid local heterogeneities, with distances between the outermost corners of the two most distant blocks ranging from 20.5 to $33.0 \mathrm{~m}$ (geometric mean: $25.4 \mathrm{~m}$ ).

\section{Field sampling}

Early in the growing season of 2013, we carefully placed and fixed iron frames subdivided into $10 \mathrm{~cm} \times 10 \mathrm{~cm}$ grid cells into the vegetation. Vegetation recordings were carried out at peak biomass in 2013 (May in Italy, Jun in Bulgaria, France, Germany and Hungary, Dec in Turkey), and the $100-\mathrm{cm}^{2}$ grid cells were temporarily subdivided by inserting a thin wooden stick in the centre of each. This resulted in $4485 \mathrm{~cm} \times 5 \mathrm{~cm}$ micro-quadrats (primary sampling units) per block and 2688 micro-quadrats per site (384 and 2304 in Bulgaria). We recorded all vascular plants (including seedlings, juveniles and recently senesced individuals) that occurred in each of the microquadrats. Two recording techniques were applied in parallel (Williamson 2003; Dengler 2008): (1) plant individuals with rooted presence only (i.e. rooting in the micro-quadrat) and (2) plant individuals with shoot presence (i.e. the plants' aerial parts fall inside the micro-quadrat when vertically projected; not recorded for Bulgaria and France).

\section{Scales, cell arrangement and statistical analyses}

Species composition and thus richness for secondary sampling units (short: sampling units) of 4, 16 and 64 cells size

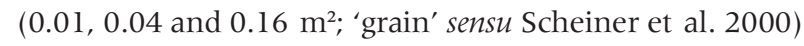
of different shapes and spatial configurations were derived by combining micro-quadrats in various ways ('computerized sampling from baseline sampling universe', sensu Podani 1987). For the comparison of elongated vs square plots, we first divided each block into 112 four-cell squares (configuration A), 28 16-cell squares and seven 64-cell squares (96, 24 and 6 in Bulgaria; Fig. 1). Next, we used full tessellation into 4:1 rectangles (configuration $\mathrm{B}$ ) with parallel orientation to the shape of the block. For 16:1 thin, elongated plots (configuration C) no full tessellation was possible; instead the maximum possible number of nonoverlapping plots were used, spread as widely as possible across each block.

For the comparison of contiguous vs discontiguous sampling units, we used the micro-quadrats described above and randomly drew the same number of these (without replacement) to derive combined richness values for dis- contiguous sampling units (Fig. 1, Appendix S2). Three cases of spatial arrangement and thus spatial extent were considered: random draw from within a sub-block of $8 \times 8$ cells (configuration D; maximum distance: $0.50 \mathrm{~m}$ ), from within a block (configuration E; maximum distance: $2.80 \mathrm{~m}$ ) and from within a site (configuration F; maximum distance: $33 \mathrm{~m}$ ). For configurations $\mathrm{D}$ and $\mathrm{E}$, we applied a nested random draw where first a random subblock or block was determined, and then the required random micro-plots were drawn within this unit.

Species richness analyses were carried out separately for rooted presence in each of the six countries, and for shoot presence in the four countries with available data (Germany, Hungary, Italy, Turkey). We tested effects of sampling unit shape separately for the three grain sizes $(4,16$ and 64 cells), using linear mixed effect models with block as random factor. To test the effect of the three discontiguous configurations vs squares of the same grain size, we calculated simple linear models. Mixed effect models were not possible in the latter case because configuration $\mathrm{F}$ contains micro-quadrats of more than one block. To make absolute richness differences comparable across sites (countries), we calculated relative richness values as $S_{\text {shape } i} / S_{\text {square, }}$ where $S_{\text {shape }}$ is the mean species richness of a certain grain size and shape. Finally, we tested whether the values of relative richness obtained for each country differed between different sampling unit configurations (i.e. different degrees of elongation or dispersion). These comparisons were carried out separately for each of the grain sizes using $t$-tests.

Both the combination of micro-quadrats into secondary sampling units and the inferential statistic tests were carried out in the R statistical environment (v.2.15.2; R Foundation for Statistical Computing, Vienna, AT) with the functions $l m e$, Im and t.test. Residuals of the derived models were visually inspected for normality and homoscedasticity (Quinn \& Keough 2002), and they did not show problematic deviations. When multiple tests were carried out with the same data set, we applied a Bonferroni correction, with $P_{\text {corr }}=P / c$, where $P$ is the probability from a single test, $P_{\text {corr }}$ the adjusted probability and $c$ the number of tests in a family of tests (Quinn \& Keough 2002). Since the Bonferroni correction is very conservative and inflates the risk of Type II errors, we accepted differences at a level of $P_{\text {corr }}<0.1$ (Quinn \& Keough 2002).

\section{Results}

\section{Effects of shape: elongated vs square plots}

Mean richness sampled as rooted presences in square plots ranged from 4.9 to 8.0 species for $0.01 \mathrm{~m}^{2}$ (four cells) and from 10.6 to 26.5 for $0.16 \mathrm{~m}^{2}$ (64 cells; Table 1). France had the lowest species richness at all grain sizes, whereas Germany had the highest species richness at $0.01 \mathrm{~m}^{2}$ and 


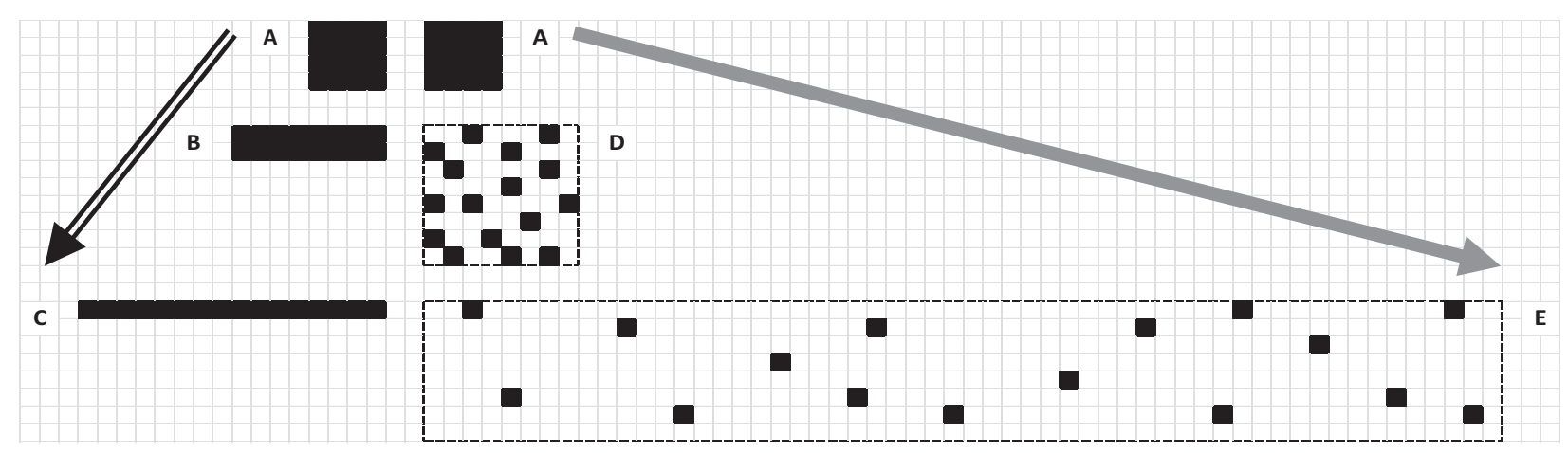

Fig. 1. Schematic visualization of the configuration of micro-quadrats that form a 16-cell sampling unit in the case of different shapes (A: 1:1; B: 4:1; C: 16:1) and spatial arrangements (A: contiguous; D: discontiguous from sub-block; E: discontiguous from block; not shown F: discontiguous from all six blocks of a site). The black arrow symbolizes the transition from a compact shape to more and more elongated shapes, and the grey arrow the transition from a contiguous configuration to more and more discontiguous (dispersed) configurations.

Italy had the highest value of species richness at 0.04 and $0.16 \mathrm{~m}^{2}$.

Plots with more elongated shapes consistently contained more rooted species on average than more compact plots $(16: 1>4: 1>1: 1)$, irrespective of country and grain size (Table 1). Due to the high spatial variation in local richness, these differences were not always significant within a single country; in Bulgaria we even found in some cases slightly and insignificantly lower values. When subjecting the country-wise means of relative richness to $t$-tests, both 4:1 rectangles and 16:1 long thin plots were significantly richer than squares, except for 4:1 rectangles of 64 cells (Fig. 2). The relative increase was consistent among countries and largely scale-invariant between the three tested grain sizes, while the shape-dependent absolute differences varied (Table 1). In general, mean richness 'gain' ranged from 2.1 to $2.3 \%$ and from 6.9 to $8.3 \%$ for comparisons between 4:1 vs $1: 1$ and between 16:1 vs 1:1 shapes, respectively, with negligible and inconsistent effects of grain size. Site had some effect, with Turkey and Italy showing the strongest relative increases, and for the two smaller grain sizes also France (Table 1). However, this did not change the overall consistent pattern, but just increased the variance towards more elongated shapes and larger grain sizes slightly (Fig. 2).

For shoot presence (Appendix S3), the richness values of the squares were consistently higher compared to rooted presence at all grain sizes. At $0.01 \mathrm{~m}^{2}$, for example, the mean increase ranged between 0.6 in Hungary and 4.2 species in Italy (Appendix S3 vs Table 1). While the overall pattern was very similar to that described for rooted presence, also the relative richness gain with decreasing compactness of the plots was higher for shoot presence than for rooted presence (Appendix S4 vs Fig. 2). For example, 16:1 plots had $10.5-12.0 \%$ more species compared to squares of the same size for shoot presence, whereas the gain was only $6.9-8.3 \%$ for rooted presence.

\section{Effects of spatial arrangement: discontiguous vs contiguous plots}

The effect of discontiguous vs contiguous configuration of micro-quadrats to form a sampling unit was much stronger than that of different degrees of compactness in the case of contiguous plots. Differences between contiguous and discontiguous sampling approaches varied depending on the degree of spatial dispersion (Table 2). Drawing from the whole site (configuration F), yielded much higher species richness values than drawing from within a block (configuration E) or a sub-block (configuration D; Table 2, Fig. 2). These differences were highly significant both in the crosscountry analysis (Fig. 2) and within countries (Table 2, with very few exceptions). As for the analyses of elongated vs squared plot, the results for different degrees of spatial dispersion were widely consistent among countries and across spatial scales. In general, drawing from a sub-block $(40 \mathrm{~cm} \times 40 \mathrm{~cm})$ produced $6.8-7.7 \%$ higher richness values, while drawing from a block $(40 \mathrm{~cm} \times 280 \mathrm{~cm})$ yielded an increase of $13.0-21.5 \%$, and drawing from the whole site an increase of 28.3$46.3 \%$ on average (Table 2 ). As with sampling unit shape, the relative effects of spatial arrangement were bigger in Turkey, Italy and France than in the other three countries.

Patterns of response for shoot presence data (Appendices S4 and S5) mirrored those presented for rooted presence, the effect sizes were even higher, but due to the small number of replicates $(n=4)$ the comparisons were not always significant (Appendix S5 vs Table 2). For example, on average, a random draw from the site (configuration $\mathrm{F}$ ) increased species richness values relative to those of 
Table 1. Species richness (rooted presence) for square plots (1:1) of four, 16 and 64 cells in size $\left(0.01 \mathrm{~m}^{2}, 0.04 \mathrm{~m}^{2}\right.$ and $\left.0.16 \mathrm{~m}^{2}\right)$ and the relative richness increase of rectangles (4:1 and 16:1) compared to squares of the same size.

\begin{tabular}{|c|c|c|c|c|c|c|c|c|}
\hline Cells & Parameter & FR & DE & BG & $\mathrm{HU}$ & IT & TR & Mean \\
\hline \multirow[t]{2}{*}{4} & Richness (1:1) & 4.9 & 8.0 & 5.3 & 5.3 & 6.5 & 7.0 & 6.2 \\
\hline & $4: 1$ vs. $1: 1, \%$ & $2.9^{*}$ & $2.6^{*}$ & $-0.3^{\text {n.s. }}$ & $1.8^{\text {n.s. }}$ & $2.5^{\text {n.s. }}$ & $4.1^{\star \star}$ & 2.3 \\
\hline \multirow[t]{3}{*}{16} & Richness (1:1) & 7.3 & 11.9 & 10.5 & 10.0 & 14.5 & 11.2 & 10.9 \\
\hline & $4: 1$ vs. $1: 1, \%$ & $2.4^{\text {n.s. }}$ & $2.3^{n .5 .}$ & $0.4^{\text {n.s. }}$ & $1.2^{\text {n.s. }}$ & $2.7^{n .5}$ & $3.8^{\text {n.s. }}$ & 2.1 \\
\hline & $16: 1$ vs. $1: 1, \%$ & $9.6^{* * *}$ & 7.7 ** & $5.0^{\text {n.s. }}$ & $7.6^{* *}$ & $9.0^{\star *}$ & $11.1^{* *}$ & 8.3 \\
\hline \multirow[t]{3}{*}{64} & Richness (1:1) & 10.6 & 16.0 & 19.4 & 16.5 & 26.5 & 17.1 & 17.7 \\
\hline & $4: 1$ vs. $1: 1, \%$ & $3.3^{\text {n.s. }}$ & $1.2^{\text {n.s. }}$ & $-1.4^{\text {n.s. }}$ & $5.0^{\text {n.s. }}$ & $2.1^{\text {n.s. }}$ & $2.7^{\text {n.s. }}$ & 2.1 \\
\hline & $16: 1$ vs. $1: 1, \%$ & $8.1^{\text {n.s. }}$ & $5.6^{\text {n.s. }}$ & $-1.2^{\text {n.s. }}$ & $7.6^{+}$ & $10.1^{\star \star *}$ & $11.3^{* \star}$ & 6.9 \\
\hline
\end{tabular}

Values are means for each of the six study sites (FR: France; DE: Germany; BG: Bulgaria; HU: Hungary; IT: Italy; TR: Turkey) and an overall mean. The results are based on separate linear mixed effect models (with block as random factor) for each country $\times$ area combination (for number of replicates in each case, see Appendix S2). Bonferroni corrections were applied to account for multiple testing within each category: ${ }^{* * *}: P_{\text {corr }}<0.001 ; * *$ : $P_{\text {corr }}<0.01$; $*: P_{\text {corr }}<0.05 ;^{+}: P_{\text {corr }}<0.1 ;{ }^{\text {n.s. }}: P_{\text {corr }} \geq 0.1$.

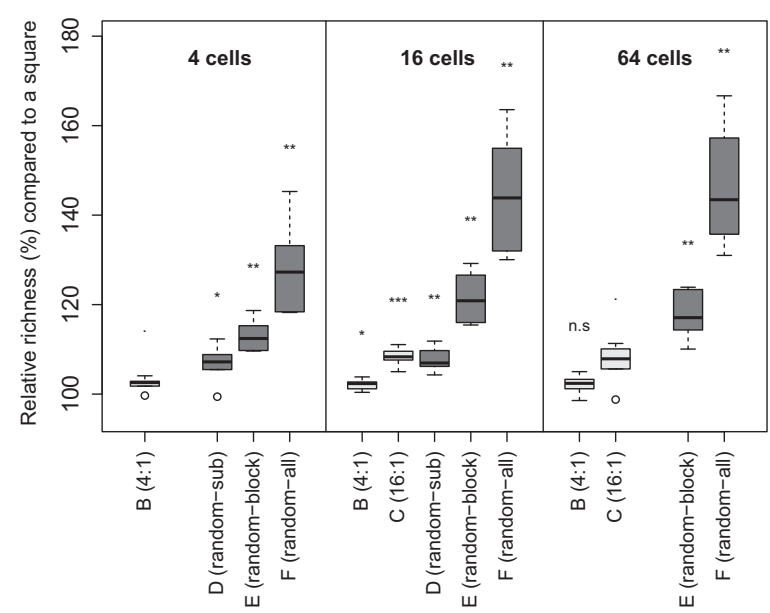

Fig. 2. Relative increase in species richness (rooted presence) compared to square plots $(1: 1)$ of the same size of various contiguous $(\mathrm{B}-\mathrm{C})$ and discontiguous (D-F) configurations of micro-quadrats of total areas of four, 16 and 64 cells $\left(0.01,0.04\right.$ and $\left.0.16 \mathrm{~m}^{2}\right)$. The box-plots are based on the mean values of the six study sites; asterisks indicate the significance of differences compared to squares (100\%), based on individual $t$-tests. The sampling designs are: $\mathrm{B}=$ rectangle with $4: 1$ ratio; $\mathrm{C}=$ thin elongated with $16: 1$ ratio; $D=$ discontiguous with random draw from within a subblock of $8 \times 8$ cells; $E=$ discontiguous with random draw from within a block; $F=$ discontiguous with random draw across all blocks of a site. This analysis is based on mean values per country $(n=6$ per combination of total area $\times$ configuration). A Bonferroni correction was applied to account for multiple testing within each grain size: $* * *$ : $P_{\text {corr }}<0.001$; $* *: P_{\text {corr }}<0.01 ; *: P_{\text {corr }}<0.05 ; \cdot: P_{\text {corr }}<0.1 ;$ n.s.: $P_{\text {corr }} \geq 0.1$.

equally sized squares by $41.0-61.6 \%$ for shoot presence compared to $28.3-46.3 \%$ for rooted presence.

\section{Discussion}

\section{Effects of plot shape}

In line with predictions and previous empirical findings (Nosek 1976; Kunin 1997; Bossuyt \& Hermy 2004), we found that plot shape, i.e. the degree of elongation of the plot, had a positive effect on species richness. In the case of rooted presence, the magnitude of elongation effects was quite small in relation to effect sizes researchers typically find when studying ecological rather than methodological drivers of biodiversity (about 2\% increase for 4:1 and $<10 \%$ for $16: 1$ rectangles compared to squares). For shoot presence the values were slightly higher (about 5\% and $12 \%$, respectively), but values for $4: 1$ shapes were still in a range that normally should not lead to erroneous conclusions in ecological studies. Note that the smaller number of 'significant' comparisons for 64 cells than for 16 cells (Table 1, Appendix S3) is largely due to reduced statistical power because of far fewer replicates in the latter case (see Appendix S2) since the effect sizes are actually very similar. Our findings are consistent with values reported in previous work with similar (Nosek 1976), slightly larger (Kunin 1997; Bossuyt \& Hermy 2004) and much larger (up to $800 \mathrm{~km}^{2}$, Kunin 1997) grain sizes. In contrast, Stohlgren (2007) found a much higher increase $(40 \%)$ in $4: 1$ rectangles of $1-\mathrm{m}^{2}$ size, but this might be attributable to the heterogeneity of their site, which they emphasize.

For practical sampling of plots in vegetation science, it is always preferable to compare species composition and diversity in sampling units with standardized shapes (preferably compact, like circles or squares). However, our study indicates that deviations from this recommendation, up to a length-width ratio of $4: 1$, are also acceptable. Including elongated plots with length-width ratios larger than $4: 1$ in the same study is also possible if the expected effect size of the factor of interest is clearly larger. Since vegetation ecologists rarely use more elongated shapes than $4: 1$, this issue normally can be ignored when taking data, for example, from large vegetation-plot databases (Dengler et al. 2011). There are, however, well-established methods, like the 'Gentry plots', frequently applied in 
Table 2. Species richness (rooted presence) for square (1:1) plots of four, 16 and 64 cells size $\left(0.01,0.04\right.$ and $\left.0.16 \mathrm{~m}^{2}\right)$ and relative richness increase for discontiguous sampling units of the same size drawn randomly from within sub-blocks of $8 \times 8$ cells (Sub), within blocks (Block) or within sites (All).

\begin{tabular}{|c|c|c|c|c|c|c|c|c|}
\hline Cells & Parameter & $F R$ & $\mathrm{DE}$ & BG & $\mathrm{HU}$ & IT & TR & Mean \\
\hline \multirow[t]{4}{*}{4} & Richness square & 4.9 & 8.0 & 5.3 & 5.3 & 6.5 & 7.0 & 6.2 \\
\hline & Sub vs $1: 1, \%$ & $8.8^{\star \star \star}$ & $6.8^{\star \star * *}$ & $-0.6^{\text {n.s. }}$ & $5.5^{\star \star}$ & $12.3^{\star \star \star}$ & $7.7^{\star \star \star \star}$ & 6.8 \\
\hline & Block vs 1:1, \% & $18.6^{* \star *}$ & $10.1^{\star \star \star}$ & $9.6^{* \star *}$ & $9.7^{* \star *}$ & $15.3^{\star \star *}$ & $14.7^{\star \star \star}$ & 13.0 \\
\hline & All vs $1: 1, \%$ & $33.2^{\star \star \star}$ & $23.5^{\star \star \star}$ & $18.3^{\star \star \star}$ & $18.4^{\star \star *}$ & $31.1 * \star \star$ & $45.2^{\star \star \star}$ & 28.3 \\
\hline \multirow[t]{4}{*}{16} & Richness square & 7.3 & 12.0 & 10.5 & 10.1 & 14.5 & 11.2 & 10.9 \\
\hline & Sub vs $1: 1, \%$ & $11.9^{* * *}$ & $4.3^{+}$ & $6.6^{*}$ & $7.3^{*}$ & $9.7 * \star \star$ & $6.2^{+}$ & 7.7 \\
\hline & Block vs 1:1, \% & $29.2^{\star \star \star}$ & $15.5^{\star \star \star}$ & $16.4^{\star \star \star}$ & $16.0 * * \star$ & $26.6^{\star \star \star}$ & $25.4^{\star \star \star}$ & 21.5 \\
\hline & All vs $1: 1, \%$ & $51.0^{\star \star \star *}$ & $30.0^{\star \star \star}$ & $36.7^{\star \star \star}$ & $31.9 * \star *$ & $54.9 * \star \star$ & $63.6^{\star \star \star}$ & 44.7 \\
\hline \multirow[t]{3}{*}{64} & Richness square & 10.6 & 16.0 & 19.4 & 16.5 & 26.5 & 17.1 & 17.7 \\
\hline & Block vs $1: 1, \%$ & $23.4^{\star \star \star}$ & $14.5^{\star \star \star}$ & $10.1^{\star}$ & $14.3^{\star \star *}$ & $19.7^{\star \star \star}$ & $23.9^{\star \star \star}$ & 17.6 \\
\hline & All vs $1: 1, \%$ & $47.2^{\star \star \star}$ & $31.0 \star \star \star$ & $39.7 * \star \star *$ & $35.7 * * *$ & $57.2^{\star \star \star}$ & $66.7 * \star *$ & 46.3 \\
\hline
\end{tabular}

Values are means for each of the six study sites (country acronyms according to Table 1) and an overall mean. The results are based on separate linear models for each country $x$ area combination (for number of replicates in each case, see Appendix S2). Bonferroni corrections were applied to account for multiple testing within each category: $* \star *: P_{\text {corr }}<0.001 ; * *: P_{\text {corr }}<0.01 ; *: P_{\text {corr }}<0.05 ;{ }^{+}: P_{\text {corr }}<0.1$; ${ }^{\text {n.s. }}: P_{\text {corr }} \geq 0.1$.

tropical (and sometimes other) forests that use such 'extreme' shapes as 25:1 rectangles for primary sampling (Phillips et al. 2003), where much stronger differences compared to squares are to be expected.

\section{Effects of spatial arrangement}

Increasing spatial dispersion, i.e. bigger distances between the micro-quadrats, led to an increase in recorded richness for a given grain size. While this is a direct and inevitable consequence of the distance decay in practically any ecological or biogeographic phenomenon (Harte et al. 1999; Nekola \& White 1999), it is rarely taken into account in studies operating with such discontiguous subplots (but see Chiarucci et al. 2009; Dengler \& Oldeland 2010). It is noteworthy that the effect of spatial dispersion was far more pronounced than that of elongated sampling units. Contiguous plots with a length-width ratio of 16:1 generally showed richness increases of around 10\%. In contrast, discontiguous sampling generated up to $90 \%$ more species (Appendix S5), despite sampling in homogenous vegetation with a maximum distance between combined microquadrats of only $33 \mathrm{~m}$.

Effects of spatial arrangement have rarely been quantified in the literature. Bacaro et al. (2015) studied this effect at the plot scale (a few square metres). While they also report higher richness for plots composed of dispersed subplots, their paper does not allow direct comparison because they only analysed the effect when combining contiguous or dispersed sampling units across a large region. Lazarina et al. (2014) conducted an extensive study on the effect of different degrees of spatial dispersion on richness values for different taxa (plants, birds, butterflies) and cell sizes (mostly distribution atlas data with grid cells of 4-100 km², but also one data set with plot-scale data and cells of $4 \mathrm{~m}^{2}$ ). Their figures for British plant atlas data indicate an increase of about $10 \%$ in richness between contiguous squares and a random sampling where about $10 \%$ of the cells within the extent were sampled. This corresponds to a degree of spatial dispersion between our configurations D (25\% cell filling) and E (3.6\%; Fig. 1), where we found increases for rooted presence of $6-8 \%$ and $13-22 \%$, respectively, at the different scales (Table 2). Finally, Dengler \& Oldeland's (2010) simulation study demonstrated that the relative difference of recorded richness for contiguous plots ('true species-area relationships') and discontiguous/dispersed plots ('species-sampling relationships') is largest for low to intermediate degrees of filling. For a filling of 16 cells out of $4096(0.3 \%)$ their figure indicates a more than twofold increase.

Taking together the comprehensive findings of Lazarina et al. (2014) for biogeographic grain sizes and ours for vegetation ecological grain sizes with the study of Dengler $\delta$ Oldeland (2010) on a fictive scale, it is clear that richness counts for dispersed subplots are nearly always higher than for a contiguous sampling unit of the same surface area. The richness increases range from about $6 \%$ for very little spatial dispersion (filling of the extent by $25 \%$ ) to more than $100 \%$ in the so far studied examples. These values for richness increase in the case of dispersed subplots can be considered to represent the lower margin of what typically is to be expected in rarefaction analyses, where vegetation is not homogenous and where the spatial dispersion is higher. Strong differences can also occur among different dispersed configurations (see Table 2 and Appendices S4 and S5, as well as Fig. 2 of Dengler \& Oldeland 2010: contrast between their SSR full and SSR centre). This indicates that comparison between different categories (vegetation types, treatments, ...) in rarefaction analyses are only sensible when not only the sampled area but also the sampled extent and the spatial configuration are kept identical. In many situations it is hard to keep extent and spatial 
arrangement patterns constant, which questions the appropriateness of rarefaction methods in such cases. Chiarucci et al. (2009) and Bacaro et al. (2012) have proposed 'spatially constrained rarefaction' as a method to overcome these limitations, which corrects for different spatial extent, provided the coordinates of the individual sampling plots are known, but this method has yet to become commonplace in vegetation studies.

Beyond rarefaction, our findings also have implications for reporting species richness. In the literature, authors often speak of species richness even when they refer to the richness derived from the combination of several discontiguous quadrats. Since we have demonstrated that 'conventional' richness (for contiguous areas) is sometimes extremely different from such values, we recommend use of the term 'cumulative species richness' for richness values from discontiguous areas, with a clear indication not only of the cumulative surface area (grain) but also the spatial extent from which they have been drawn.

What this means in practice will shortly be discussed with a typical example from the literature: Öster et al. (2007) reported a 'mean species density on $10 \mathrm{~m}^{2 \prime}$ of 57.1 vascular plants for Swedish grasslands, which seems to be close to the "world record grasslands' at the $10-\mathrm{m}^{2}$ grain size in Romania (Wilson et al. 2012), which have a mean richness of 70.2 vascular plants (Dengler et al. 2012). On closer inspection, however, both values are not comparable because the areas of Öster et al. (2007) are composed of ten subplots randomly drawn from areas of $0.2-18.9$ ha (mean: $5.6 \mathrm{ha}$ ). This corresponds to a 'cell filling' of, on average, $<0.02 \%$, which is far sparser than in the examples discussed above so that we can assume that the reported value of 57.1 species is significantly higher than the average richness in a contiguous 10$\mathrm{m}^{2}$ plot in their area. While the authors correctly reported these details of their methods in the text, the shortened terminology of the diversity variables in their table could prompt misunderstandings. A clear and explicit terminology would help to avoid this. Similarly, the term 'vegetation plot' or short 'plot' should be restricted to contiguous sampling units. Accordingly, the 'Gentry plots', one of the most widespread sampling approaches for tropical forests (Baraloto et al. 2013), should not be termed 'plots' any longer (nor be stored as single 0.1-ha plots in vegetation databases) as is widespread practice, but named as what they are: complex sampling schemes, where ten discontiguous $100-\mathrm{m}^{2}$ subplots are combined to form a secondary sampling unit (Phillips et al. 2003). Based on the points discussed here, such 0.1-ha 'Gentry plots' are not comparable to conventional (contiguous) 0.1-ha plots as regards species composition and diversity metrics.

\section{Generalities and idiosyncrasies}

Overall, the observed increases in richness with decreasing compactness of the configurations of micro-quadrats were highly consistent across sites, grain sizes and recording methods (rooted vs shoot presence). The fact that we included grasslands from two zonobiomes (Nemoral and Mediterranean, as well as a transition Nemoral-Steppic) with quite different climates and land-use history underlines the generality of the results. Since we selected areas within the grassland sites that were relatively homogenous in terms of topography and vegetation physiognomy, our values for richness increase can be considered to be at the lower margin of what can be found in randomly located plots. Larger gains should be expected in more heterogeneous vegetation (Bartha \& Horváth 1987). To assess the generality of our findings we thus recommend conducting similar studies in more heterogeneous and more complex vegetation, as well as for larger grain sizes.

The slight differences between countries regarding the richness gain with decreasing compactness could thus be attributable to the different levels of homogeneity that could be achieved locally. Consistently high richness gains with decreasing compactness across all 13 comparisons were found (in this sequence) for Turkey, France and Italy in the case of rooted presence (Tables 1 and 2) and for Italy and Turkey in the case of shoot presence (Appendices S3 and S4), whereas the sites in Germany, Bulgaria and Hungary usually showed the lowest increase. While we did not attempt to measure abiotic site heterogeneity, this ranking coincides with the particularly high visible site heterogeneity of the Turkish site (many stones of different sizes at or near the surface, variable microtopography) and the known small-scale heterogeneity in historic land use in the Italian site. Taking a simple $\beta$-diversity measure (cumulative richness of all blocks of a country / mean rooted richness of $10 \mathrm{~cm} \times 10 \mathrm{~cm}$; Appendix S1), Italy also had by far the most heterogeneous vegetation, but France and Italy were only in the middle range. In contrast, Germany with the on average lowest richness gains, was also the country with the lowest $\beta$-diversity value and a visually particularly homogenous stand.

Regarding the recording methodology, the relative increase of richness (in percentage) for the same spatial configuration was nearly always higher for shoot presence than for rooted presence, typically with a factor of approx. 1.5 (see Tables 1 and 2, Appendices S3, S4 and S6). This could be explained by the increasing length of the margin in less compact sampling units, which directly influences the richness in the case of rooted presence (e.g. Dengler 
2003), but only indirectly via vicinism (i.e. 'atypical' species that occur inside the plot only due to high diaspore pressure from neighbouring communities) in the case of rooted presence.

Grain size had limited effects on relative richness gains compared with site-specific factors or recording methodology. Indeed, mean richness gains for 4:1 vs 1:1 plots were nearly indistinguishable between grain sizes of $0.01,0.04$ and $0.16 \mathrm{~m}^{2}$ for rooted presence (see Table 1 ), and varied only moderately in response to spatial arrangement (see Table 2). While for logistical reasons (work effort) we could only study very small grain sizes, this relative scale invariance indicates that the patterns will likely remain similar for grain sizes that are one to three orders of magnitude larger, thus in the normal range of vegetation plots in herbaceous vegetation (Chytrý \& Otýpková 2003). Other studies have demonstrated that the slope of the speciesarea relationship (which is closely related to the distance decay) often remains relatively constant over many orders of magnitude (Dengler \& Boch 2008; Wilson et al. 2012).

\section{Consequences for future studies}

Clear guidelines on vegetation recording are critical for accurate assessments and monitoring of species richness and biodiversity responses to global change. Our key findings are that richness values of sampling units with very different compactness and spatial arrangement are not directly comparable. The concept of 'effective area' may however help overcome this problem and allow robust cross-site comparisons (Lazarina et al. 2014). Effective area $A_{e}$ is here defined as the equivalent square-shaped area that contains the same number of species as an elongated, dispersed or otherwise irregular sampling unit. While Lazarina et al. (2014) required $A_{e}$ only to be contiguous, we more precisely specify it to be square-shaped to also allow comparison between contiguous sampling plots of different compactness. While circles are even more compact than squares, their richness values in reality differ only negligibly from those of squares (Stohlgren 2007 and see extrapolation below); moreover, circular sampling units are rare for vegetation data and inexistent for atlas data, so that using squares as baseline is sensible.

Applying the concept of effective area to our results (Appendix S6) provides an easily understandable interpretation of the effects of different configurations of sampling units. For rooted presence and $0.01 \mathrm{~m}^{2}$, for example, a $4: 1$ rectangle was on average as rich as a square of the 1.06fold area, while randomly dispersed micro-quadrats within the whole site correspond to a square of 1.93-fold area. The largest relative $A_{e}$ for means across countries of 4.51 was found for the latter configuration in the case of 0.04$\mathrm{m}^{2}$ grain size and shoot presence (Appendix S6). The maxi- mum value for an individual site was even 6.05 for this configuration and $0.01-\mathrm{m}^{2}$ grain size in Turkey (not shown). Among others, Appendix S6 demonstrates that 16:1 rectangles and a sampling unit consisting of 16 microquadrats randomly distributed within an $8 \times 8$ square had a similar effective area of 1.23 times that of a contiguous square (rooted presence; 1.45 times for shoot presence).

Another way to compare different spatial configurations of sampling plots is to quantify and test the effects of their spatial extents, $A_{\text {extent }}$. Here we propose to define $A_{\text {extent }}$ as the area of the smallest circle that encompasses the complete sampling unit. We refer to a circle because this is the most compact configuration possible. In this way the spatial extents of any spatial configuration, be it regular or irregular, contiguous or discontiguous, can be compared in a single framework. When at the same time the grain size is kept constant, this allows calculating species-extent relationships (SERs) similar to species-area relationships (SARs), which we introduce here as a new concept in analogy to the also equivalent species-time relationships (STRs) introduced by Adler \& Lauenroth (2003). Doing so for the mean values of rooted presence at $0.01-\mathrm{m}^{2}$ grain size across all six countries yields an unexpectedly tight relationship, with $R^{2}=0.995$ (Fig. 3), despite the very different spatial configurations involved. With a $z$-value (slope in double-logarithmic space) of only 0.041 , the species increase with increasing spatial extent is much lower than with increasing grain size (there we had a $z$-value of 0.378 ) but still appreciable, which is in agreement with the findings of Palmer $\delta$ White (1994) and Palmer et al. (2002). Since this relationship is so tight, one can use it for predicting richness differences of any spatial configuration of sampling units totalling $0.04 \mathrm{~m}^{2}$ relative to a square of that size. Using the regression function, for example, a circle of $0.04 \mathrm{~m}^{2}$ in our grasslands would only have $1.8 \%$ fewer species than a square - no wonder that Stohlgren (2007) with his few replicates could not find any significant difference in such a comparison. Taking species-area and speciesextent relationships together in a species-area-extent relationship (SAER) analogous to the species-time-area relationship (STAR) of Adler \& Lauenroth (2003), and like them assuming power functions (as they were well supported here and in many other studies), one obtains:

$$
\log S=\log c+z \log A+z_{\text {extent }} \log A_{\text {extent, relative }},
$$

with $S=$ species richness, $A=$ surface area of the sampling unit, $A_{\text {extent, relative }}=$ area of the circle that comprises the whole sampling unit, standardized by the area of a circle that comprises a square of the same surface area, $z=$ slope of the species-area relationship, $z_{\text {extent }}=$ slope of speciesextent relationship. Note that like STARs (Adler \& Lauen- 


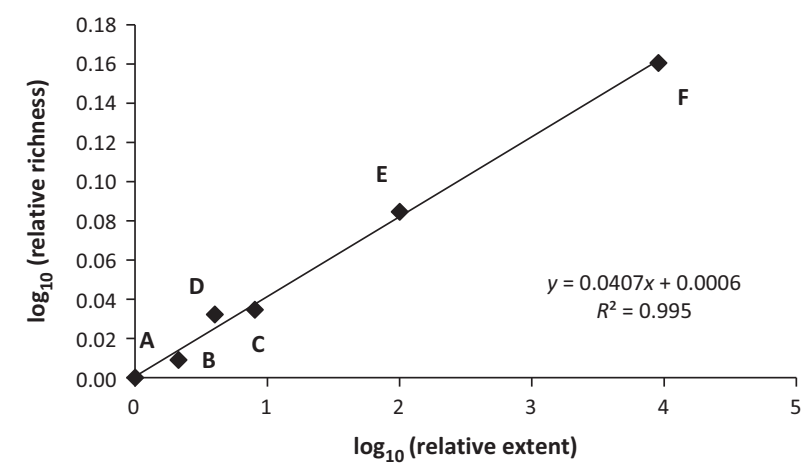

Fig. 3. Example of a species-extent relationship (SER) for a comparison of our six different spatial configurations (square, two types of rectangle, three types of dispersed plot) for $0.04 \mathrm{~m}^{2}$, shoot presence and means across all six countries. Both axes are standardized by the values of a square, i.e. the square appears in the origin of the graph. The regression was calculated in log-log space (function given in the figure), in linear space, it would read: relative richness $=1.0013$ (relative extent) ${ }^{0.0407}$. The letters indicate the spatial configuration according to Fig. 1. Note that the relative extent for the least compact configuration (micro-quadrats dispersed across all blocks of a site) varies somewhat across countries and is here given as the geometric mean.

roth 2003) also SAERs might include an interaction term between area (grain) and extent, as suggested by Palmer \& White (1994), but our data set was too limited to test for significance of such a term.

Finally, considering the typical richness gains of various spatial configurations of sampling units, how should species richness data then be best sampled? Some researchers have suggested that one sampling approach is preferable over another if it finds more species on the same area $A$ of the combined sampling units (e.g. Stohlgren 2007; Bacaro et al. 2015). They argue that spatial configurations with maximum ratio of $A_{e} / A$ (i.e. with high length-width ratio or high spatial dispersion) would be preferable because one would find more species on the same area. This line of reasoning is however questionable for two reasons. First, the additional effort for delimiting more complicated sampling units with increased border length will often increase the overall time needed to record one species on average. Second, obtaining high richness values is generally less important than the ability to compare values with those from similar studies. We believe that a square sampling unit, despite having a very low effective area, is the most advantageous shape. This, together with the fact that the large majority of legacy data have been sampled on square plots, makes compact squares in most cases the best choice for sampling units.

\section{Acknowledgements}

This work is part of the project SIGNAL, coordinated by A.J., which is mainly funded by the ERA-Net BiodivERsA (http://www.biodiversa.org), with the national funders German Federal Ministry of Education and Research (BMBF), Bulgarian Science Found and Ministère de l'Écologie, du Développement durable et de l'Énergie (France) as part of the 2011-2012 BiodivERsA call for research proposals. The particular study is part of the $\mathrm{PhD}$ thesis of B.G., whose research stay in Bayreuth was made possible through a grant from the Bayerische Forschungsstiftung to J.D. We thank Marco Cervellini, Stefano Chelli, Kevin Cianfaglione, Kerstin Grant, Alexandre Salcedo, Desislava Sopotlieva and Jasen Stoyanov for help with the field sampling. Finally, we are grateful to János Podani as co-ordinating editor and three anonymous referees who, with their thoughtful comments, significantly contributed to the final quality of this article.

\section{Author Contribution}

The study was planned by J.D., while field sampling was conducted by B.G., C.W., G.C., G.S, I.A., J.B., J.D., J.H., J.P, R.C., S.B., T.T. and Z.Z. Statistical analyses were carried out by J.K., J.D. and B.G. The Methods and Results sections were drafted by B.G. and the Introduction and Discussion by J.D., with all other co-authors contributing to the interpretation of the results and the revision of the text.

\section{References}

Adler, P.B. \& Lauenroth, W.K. 2003. The power of time: spatiotemporal scaling of species diversity. Ecology Letters 6: 749756.

Arrhenius, O. 1921. Species and area. Journal of Ecology 9: 95-99. Bacaro, G., Rocchini, D., Ghisla, A., Marcantonia, M., Neteler, M. \& Chiarucci, A. 2012. The spatial domain matters: spatially constrained species rarefaction in a free and open source environment. Ecological Complexity 12: 63-69.

Bacaro, G., Rocchini, D., Diekmann, M., Gasparini, P., Gioria, M., Maccherini, S., Marcantonio, M., Tordoni, E., Amici, V., (...) \& Chiarucci, A. 2015. Shape matters in sampling plant diversity: evidence from the field. Ecological Complexity 24: $37-45$.

Baraloto, C., Molto, Q., Rabaud, S., Hérault, B., Valencia, R., Blanc, L., Fine, P.V.A. \& Thompson, J. 2013. Rapid simultaneous estimation of aboveground biomass and tree diversity across Neotropical forests: a comparison of field inventory methods. Biotropica 45: 288-298. 
Bartha, S. \& Horváth, F. 1987. Application of long transects and information theoretical functions to pattern detection. I. Transects versus isodiametric sampling units. Abstracta Botanica 11: 9-26.

Bossuyt, B. \& Hermy, M. 2004. Species turnover at small scales in dune slack plant communities. Basic and Applied Ecology 5: 321-329.

Chiarucci, A., Bacaro, G., Rocchini, D., Ricotta, C., Palmer, M.W. \& Scheiner, S.M. 2009. Spatially constrained rarefaction: incorporating the autocorrelated structure of biological communities into sample-based rarefaction. Community Ecology 10: 209-214.

Chytrý, M. \& Otýpková, Z. 2003. Plot sizes used for phytosociological sampling of European vegetation. Journal of Vegetation Science 14: 563-570.

Connor, E.F. \& McCoy, E.D. 1979. The statistics and biology of the species-area relationship. The American Naturalist 113: 791-833.

Dengler, J. 2003. Entwicklung und Bewertung neuer Ansätze in der Pflanzensoziologie unter besonderer Berücksichtigung der Vegetationsklassifikation. Archiv naturwissenschaftlicher Dissertationen 14: 1-297.

Dengler, J. 2006. Variabilität von Artendichte und Artenzusammensetzung auf unterschiedlichen räumlichen Skalenebenen - Exemplarische Untersuchungen aus Trockenrasen und Konsequenzen für das Probedesign von Biodiversitätsuntersuchungen. Arbeiten aus dem Institut für Landschaftsökologie Münster 15: 73-81.

Dengler, J. 2008. Pitfalls in small-scale species-area sampling and analysis. Folia Geobotanica 43: 269-287.

Dengler, J. 2009. Which function describes the species-area relationship best? - A review and empirical evaluation. Journal of Biogeography 36: 728-744.

Dengler, J. \& Boch, S. 2008. Sampling-design effects on properties of species-area curves - A case study from Estonian dry grassland communities. Folia Geobotanica 43: 289-304.

Dengler, J. \& Oldeland, J. 2010. Effects of sampling protocol on the shapes of species richness curves. Journal of Biogeography 37: 1698-1705.

Dengler, J., Jansen, F., Glöckler, F., Peet, R.K., De Cáceres, M., Chytrý, M., Ewald, J., Oldeland, J., Lopez-Gonzalez, G., (...) \& Spencer, N. 2011. The Global Index of Vegetation-Plot Databases (GIVD): a new resource for vegetation science. Journal of Vegetation Science 22: 582-597.

Dengler, J., Becker, T., Ruprecht, E., Szabó, A., Becker, U., Beldean, M., Bita-Nicolae, C., Dolnik, C., Goia, I., (...) $\delta$ Uğurlu, E. 2012. Festuco-Brometea communities of the Transylvanian Plateau (Romania) - a preliminary overview on syntaxonomy, ecology, and biodiversity. Tuexenia 32: 319359.

Dierschke, H. 1994. Pflanzensoziologie - Grundlagen und Methoden. Ulmer, Stuttgart, DE.

Gotelli, N.J. \& Colwell, R.K. 2001. Quantifying biodiversity: procedures and pitfalls in the measurement and comparison of species richness. Ecology Letters 4: 379-391.
Gotelli, N.J. \& Colwell, R.K. 2011. Estimating species richness. In: Magurran, A.E. \& McGill, B.J. (eds.) Biological diversity: frontiers in measurement and assessment, pp. 39-54. Oxford University Press, Oxford, UK.

Harte, J., Kinzig, A.P. \& Green, J. 1999. Self-similarity in the distribution and abundance of species. Science 284: 334-336.

Heegaard, E., Økland, R.H., Bratli, H., Dramstad, W.E., Engan, G., Pedersen, O. \& Solstad, H. 2007. Regularity of species richness relationships to patch size and shape. Ecography 30 : 589-597.

Jentsch, A., Kreyling, J., Apostolova, I., Bahn, M., Bartha, S., Beierkuhnlein, C., Bloor, J., de Boeck, H., Dengler, J., (...) \& SIGNAL PhD students. 2014. Joining biodiversity experiments, climate change research and invasion biology to assess European gradients of grassland resilience in the face of climate extremes. In: Mucina, L., Price, J.N. \& Kalwij, J.M. (eds.) Biodiversity and vegetation: patterns, processes, conservation, pp. 114-114. Kwongan Foundation, Perth, AU.

Keeley, J.E. \& Fotheringham, C.J. 2005. Plot shape effects on plant species diversity measurements. Journal of Vegetation Science 16: 249-256.

Kenkel, N.C., Juhasz-Nagy, P. \& Podani, J. 1989. On sampling procedures in population and community ecology. Vegetatio 83: 195-207.

Kent, M. 2012. Vegetation description and data analysis - a practical approach. Wiley-Blackwell, Chichester, UK.

Knapp, R. 1984. Sample (relevé) areas (distribution, homogeneity, size, shape) and plot-less sampling. In: Knapp, R. (ed.) Sampling methods and taxon analysis in vegetation science: Relevé surveys, 'Vegetationsaufnahmen', floristic analysis of plant communities, pp. 101-119. Dr. W Junk, The Hague, NL.

Koellner, T., Hersperger, A.M. \& Wohlgemuth, T. 2004. Rarefaction method for assessing plant species diversity on a regional scale. Ecography 27: 532-544.

Kunin, W.E. 1997. Sample shape, spatial scale and species counts: implications for reserve design. Biological Conservation 82: 369-377.

Lazarina, M., Kallimanis, A.S., Pantis, J.D. \& Sgardelis, S.P. 2014. Linking species richness curves from non-contiguous sampling to contiguous-nested SAR: an empirical study. Acta Oecologica 61: 24-31.

Li, H. \& Reynolds, J.F. 1995. On definition and quantification of heterogeneity. Oikos 73: 280-284.

Nekola, J.C. \& Brown, J.H. 2007. The wealth of species: ecological communities, complex systems and the legacy of Frank Preston. Ecology Letters 10: 188-196.

Nekola, J.C. \& White, P.S. 1999. The distance decay of similarity in biogeography and ecology. Journal of Biogeography 26: 867-878.

Nosek, J.N. 1976. Comparative analysis of some diversity functions under different conditions of sampling in sandy meadow. Acta Botanica Scientiarum Hungaricae 22: 41 5-436.

Öster, M., Cousins, S.A.O. \& Eriksson, O. 2007. Size and heterogeneity rather than landscape context determine plant spe- 
cies richness in semi-natural grasslands. Journal of Vegetation Science 18: 859-868.

Palmer, M.W. \& White, P.S. 1994. Scale dependence and the species-area relationship. The American Naturalist 144: 717740.

Palmer, M.W., Earls, P.G., Hoagland, B.W., White, P.S. \& Wohlgemuth, T. 2002. Quantitative tools for perfecting species lists. Environmetrics 13: 121-137.

Phillips, O.L., Vásquez Martínez, R., Núñez Varga, P., Lorenzo Monteagudo, A., Chuspe Zans, M.-E., Galiano Sánchez, W., Peña Cruz, A., Timaná, M., Yli-Halla, M. \& Rose, S. 2003. Efficient plot-based floristic assessment of tropical forests. Journal of Tropical Ecology 19: 629-645.

Podani, J. 1987. Computerized sampling in vegetation studies. Coenoses 3: 9-18.

Quinn, G.P. \& Keough, M.J. 2002. Experimental design and data analysis for biologists. Cambridge University Press, Cambridge, UK.

Scheiner, S.M., Cox, S.B., Willig, M., Mittelbach, G.G., Osenberg, C. \& Kaspari, M. 2000. Species richness, species-area curves and Simpson's paradox. Evolutionary Ecology Research 2: 791-802.

Shmida, A. \& Wilson, M.V. 1985. Biological determinants of species diversity. Journal of Biogeography 12: 1-20.

Stiles, A. \& Scheiner, S.M. 2007. Evaluation of species-area functions using Sonoran Desert plant data: not all species-area curves are power functions. Oikos 116: 1930-1940.

Stohlgren, T.J. 2007. Measuring plant diversity - lessons from the field. Oxford University Press, Oxford, UK.

Tobler, W.R. 1970. A computer movie simulating urban growth in the Detroit region. Economic Geography, Supplement 46: 234-240.

Williamson, M. 2003. Species-area relationships at small scales in continuum vegetation. Journal of Ecology 91: 904-907.

Wilson, J.B., Peet, R.K., Dengler, J. \& Pärtel, M. 2012. Plant species richness: the world records. Journal of Vegetation Science 23: 796-802.
Zonneveld, I.S. 1994. Vicinism and mass effect. Journal of Vegetation Science 5: 441-444.

\section{Supporting Information}

Additional Supporting Information may be found in the online version of this article:

Appendix S1. Characterisation of the study sites, arranged according to increasing mean annual temperature.

Appendix S2. Number of replicates for the different grain sizes and spatial configurations in France, Germany, Hungary, Italy and Turkey (General) and Bulgaria (BG), respectively.

Appendix S3. Species richness (shoot presence) for square (1:1) plots of 4,16 and 64 cells size $\left(0.01 \mathrm{~m}^{2}, 0.04\right.$ $\mathrm{m}^{2}$ and $\left.0.16 \mathrm{~m}^{2}\right)$ and the relative richness increase of rectangles (4:1 and 16:1) compared to squares of the same size.

Appendix S4. Relative increase in species richness (shoot presence) of various contiguous (B-C) and discontiguous (D-F) configurations of micro-quadrats of total areas of 4,16 and 64 cells $\left(0.01,0.04\right.$ and $\left.0.16 \mathrm{~m}^{2}\right)$ compared to squared plots $(1: 1)$ of the same size (A).

Appendix S5. Species richness (shoot presence) for square (1:1) plots of 4,16 and 64 cells size $\left(0.01 \mathrm{~m}^{2}, 0.04\right.$ $\mathrm{m}^{2}$ and $0.16 \mathrm{~m}^{2}$ ) and the relative richness increase for discontiguous sampling units of the same size drawn randomly from within subblocks of $8 \times 8$ cells (Sub), within blocks (Block) or within sites (All).

Appendix S6. Effective areas that correspond to the five different spatial configurations of sampling units used for richness counts as compared in this study. 